\title{
Educậão cristã on-life: por um ensino integral e sinodal nos espaços físicos e digitais
}

\section{On-life christian education: for integral and synodal education in physical and digital spaces}

\author{
Aline Amaro da Silva* \\ PUC-RS
}

Recebido em: 08/11/2021. Aceito em: 16/11/2021.

Resumo: O pacto educativo global, bem como a Campanha da Fraternidade de 2022, nos impelem a (re)pensar a educação cristã na contemporaneidade. A pandemia fez com que o ensino migrasse para o ambiente digital, acelerando o processo de digitalização, desconstruindo a ideia dos espaços físico e digital serem vistos como realidades separadas, fazendo-nos adentrar em uma nova experiência de mundo: a era on-life. Diante das pautas em que a lgreja se propõe a refletir no contexto atual, o presente artigo busca caminhos para uma educação cristã on-life, que se guie por dois princípios fundamentais: a integralidade e a sinodalidade. Através de pesquisa bibliográfica, discorremos sobre o conceito de educação trabalhado pela Campanha da Fraternidade 2022, os desafios e contribuições da era on-life para o ensino-aprendizagem e ainda a sugestão da abordagem de Interação Centrada no Tema (ICT) como possibilidade de caminho para uma educação cristã integral e sinodal.

Palavras-chave: Educação Integral. Era On-life. Sinodalidade. Interação Centrada no Tema.

Abstract: The global educational pact, as well as the Fraternity Campaign of 2022, urge us to (re)think about Christian education in contemporary times. The pandemic has made teaching migrate to the digital environment, accelerating the digitalization process, deconstructing the idea that physical and digital spaces

* Doutora em Teologia (Pontifícia Universidade Católica do Rio Grande do Sul, PUC-RS, Porto Alegre, RS, com período sanduíche em Ruhr-Universität Bochum, Alemanha, 2021). Mestra em Teologia (Pontifícia Universidade Católica do Rio Grande do Sul, PUC-RS, Porto Alegre, RS, 2015). Graduada em Comunicação Social (Pontifícia Universidade Católica do Rio Grande do Sul, PUC-RS, Porto Alegre, RS, 2011). Professora Adjunta do ANIMA - PUC Minas.

E-mail: aline.amaro@acad.pucrs.br. 
are seen as separate realities, making us enter a new world experience: the on-life era. In view of the guidelines that the Church proposes to reflect on in the current context, the present article seeks ways for a Christian on-life education that is guided by two fundamental principles: integrality and synodality. Through bibliographical research, we discuss the concept of education worked by the Fraternity Campaign 2022, the challenges and contributions of the on-life era for teaching-learning, and also the suggestion of the Theme-Centered Interaction (ICT) approach as a possible path for an integral and synodal Christian education.

Keywords: Integral Education. On-life era. Synodality. Theme-Centered Interaction.

\section{Introdução}

A reforma da consciência e a maturação do senso crítico, ecológico, humanístico e planetário só será possível através da educação. Ciente disso e , em continuidade com a proposta apresentada na Evangelii Gaudium e Laudato Si de construir bases para trabalharmos pela "casa comum", o Papa Francisco lança o convite a fazermos parte do Pacto Educativo Global. Esta aliança educativa, visa "reavivar o compromisso em prol e com as gerações jovens, renovando a paixão por uma educação mais aberta e inclusiva, capaz de escuta paciente, diálogo construtivo e mútua compreensão". ${ }^{1}$

Correspondendo ao chamado do Papa Francisco, a Conferência Nacional dos Bispos do Brasil escolheu para a Campanha da Fraternidade de 2022 o tema "Fraternidade e Educação", e o lema: "Fala com sabedoria, ensina com amor" $(\operatorname{Pr} 31,26)$. Diante deste panorama, o presente artigo busca refletir sobre a educação cristã em todos os espaços que o ser humano habita, em vista de um caminho de ensino integral, caracterizado pela sinodalidade. Assim, o breve estudo acrescenta ao debate educativo o fenômeno digital que permeia e molda nossa vida cotidiana a tal ponto que não podemos mais separá-la da nossa vida real, fazendo-nos ingressar na era on-life, termo cunhado pelo filósofo Luciano Floridi.

No início do Texto-base da Campanha da Fraternidade de 2022 diz que educar é uma ação profundamente humana e divina, pois educar é próprio de quem ama. ${ }^{2}$ Educar e comunicar são atitudes inerentes aos

1 FRANCISCO. Mensagem do Papa Francisco para o Lançamento do Pacto Educativo. Roma, 2019. Disponível em: https://www.vatican.va/content/francesco/pt/messages/ pont-messages/2019/documents/papa-francesco_20190912_messaggio-patto-educativo.pdf. Acesso em: 29 out. 2021.

2 CNBB. CF 2022 - Texto-base. Brasília, DF: Edições CNBB, 2021. Edição do Kindle. 
seres humanos e a Deus, pois Deus em sua autocomunicação, quis nos ensinar sobre si mesmo, sobre o sentido, valor e dignidade da pessoa humana e do mundo. Sendo assim, educar e comunicar são atos que fazem as pessoas serem verdadeiramente humanas e cada vez mais semelhantes ao Grande Mestre e Comunicador da Vida. Tudo se aprende de alguém ou com alguém: comer, beber, caminhar, falar, aprender a aprender, rezar. É no entendimento e busca de uma educação integral e sinodal que a Campanha da Fraternidade 2022 se inspira e quer inspirar as brasileiras e brasileiros.

Por meio de pesquisa bibliográfica, este artigo pretende contribuir na reflexão sobre os seguintes objetivos da Campanha da Fraternidade:

Analisar o contexto da educação na cultura atual, e seus desafios potencializados pela pandemia; [...] [Auxiliar na construção de] uma educação humanizadora na perspectiva do Reino de Deus; [...] Incentivar propostas educativas que, enraizadas no Evangelho, promovam a dignidade humana, a experiência do transcendente, a cultura do encontro e o cuidado com a casa comum. ${ }^{3}$

O estudo aponta como alternativa para o desenvolvimento de uma educação cristã on-life a prática da Interação Centrada no Tema, uma abordagem holística pensada pela psicoterapeuta judia-alemã Ruth Cohn como caminho de humanização contra o fascismo. Nos tempos sombrios e polarizados que presenciamos, o ICT demonstra sua relevância e atualidade para uma educação para a paz, senso crítico, maturidade e sinodalidade.

\section{Princípios e itinerário de educação cristã integral apontados pela Campanha da Fraternidade 2022}

Inspirado no método ver, julgar e agir, o caminho que a Campanha da Fraternidade de 2022 propõe para repensar a educação é o da escuta, do discernimento e da ação. ${ }^{4}$ É interessante essa troca de conceito nas duas primeiras etapas, pois escutar requer proximidade, encontro, sair da zona de conforto e passividade que um olhar à distância permite. ${ }^{5}$ "É uma escuta integral, com o ouvido e com o coração, que buscam a

3 CNBB. CF 2022 - Texto-base.

4 CNBB. CF 2022 - Texto-base, n. 141.

5 CNBB. CF 2022 - Texto-base, n. 26. 
inteireza da realidade com tudo o que ela pode trazer". ${ }^{6}$ Discernir também é mais abrangente do que julgar, é analisar os fatos e as pessoas envolvidas sob a ótica do Ressuscitado: "[...] o discernimento se pratica com outra escuta, dessa vez, da Palavra de Deus, como passo fundamental para julgar evangelicamente os desafios do tempo presente e apontar as proposições para o novo". ${ }^{7}$

Esta é a postura de uma Igreja que deseja trilhar o caminho sinodal em saída missionária, que quer realizar um processo de "conversão do coração, verdadeira mudança de vida que se dá a partir do encontro pessoal com Jesus Cristo". ${ }^{8}$ Para pensar nos fundamentos da educação cristã, precisamos revisitar suas fontes.

A exemplo dos testemunhos do Antigo e Novo Testamento que narram a relação próxima entre Deus e as pessoas humanas, a Campanha da Fraternidade 2022 propõe um "caminhar juntos", um acompanhamento educativo. A pedagogia de Jesus é desenvolvida através de uma presença atenciosa e ativa, encarnada, que traz exemplos da vida diária das pessoas, do contexto, do clima, da natureza, da história local. Nesse espírito cristão, o ensino integral visa educar para a fraternidade e amizade social, promovendo a escuta, o diálogo, a reciprocidade e o crescimento em conjunto. A Campanha da Fraternidade resgata os princípios fundamentais que constituem a educação numa linha de continuidade do processo de reflexão das mensagens anteriores que passa pelo compromisso de cuidar de cada ser vivo e do meio ambiente. A leitura do texto, faz o educador se questionar: O que me motiva a educar? Em que consiste o ato de educar? Qual é o meu papel como educador no ensino da era digital?

$\mathrm{Na}$ concepção cristã, "educar é contribuir para a superação do pecado, preservando a vida, atingindo as consciências e transformando relações. [...] É encontro no qual todos são educadores e educandos". ${ }^{9}$ Por isso, o texto explica que é preciso de uma comunidade colaborativa, uma aldeia, uma família, rede de apoiadores para se educar alguém, seja uma criança, um jovem, um adulto.

A educação é alicerce para a construção da fraternidade humana. Educar para a comunhão missionária requer esforço de revisão de vida

\footnotetext{
6 CNBB. CF 2022 - Texto-base, n. 29.

7 CNBB. CF 2022 - Texto-base, n. 139.

8 CNBB. CF 2022 - Texto-base.

9 CNBB. CF 2022 - Texto-base.
} 
e conversão dos próprios educadores a fim de exercerem uma autoridade baseada não na função, mas na autenticidade de vida. Inspirada no Pacto Educativo Global do Papa Francisco, a Campanha da Fraternidade propõe uma educação humanizada e humanizadora "que contribua na formação de pessoas abertas, integradas e interligadas, que também sejam capazes de cuidar da casa comum". ${ }^{10}$

Todo ambiente de convivência humana são lugares de aprendizagem, cada um com diferentes tipos e níveis de compartilhamento de saberes: o lar, o colégio, o trabalho, o parque, as mídias, os games, a Igreja. A Encíclica Laudato Si, n. 213, traz a família como sede da cultura da vida, pois é no ambiente familiar que se criam os hábitos elementares de amor e cuidado com o humano e com a criação.

A família é o lugar da formação integral, onde se desenvolvem os distintos aspectos, intimamente relacionados entre si, do amadurecimento pessoal. Na família, aprende-se a pedir licença sem servilismo, a dizer "obrigado" como expressão duma sentida avaliação das coisas que recebemos, a dominar a agressividade ou a ganância, e a pedir desculpa quando fazemos algo de mal. Estes pequenos gestos de sincera cortesia ajudam a construir uma cultura da vida compartilhada e do respeito pelo que nos rodeia (LS 213).

Durante a pandemia, especialmente na quarentena de 2020, todos os ambientes de aprendizagem convergiram para o meio familiar. A mãe e o pai acumularam as funções de professores, catequistas, instrutores, além de continuarem seu trabalho home office. Em algumas realidades essa experiência resgatou e fortaleceu o sentido de igreja doméstica e a missão da educação integral da família. Em outras, a sobrecarga levou a mais violência familiar, feminicídios e separações de casais. "Em um tempo marcado pela pandemia da COVID-19 e por diversos conflitos, distanciamentos e polarizações, é preciso reaprender a amar, a perdoar, a cuidar, a curar, a dialogar e a servir a todos". ${ }^{11}$ Palavras simples, mas de difícil prática, especialmente em momentos de tensão como os atuais.

A partir do relato bíblico neotestamentário da mulher flagrada em adultério (Jo 8,2-11), o texto da Campanha da Fraternidade apresenta dois caminhos pedagógicos opostos que frequentemente nos deparamos na interpretação e prática cristã: “[...] a daqueles que se restringem ao que está

10 CNBB. CF 2022 - Texto-base, n. 7.
$11 \quad$ CNBB. CF 2022 - Texto-base, n. 8. 
escrito, sem levar em conta a pessoa e suas circunstâncias, e daqueles que olham para a pessoa com sabedoria e amor, como fez Jesus"12. Jesus é o modelo de educador que escuta com paciência e atenção, fala sabiamente quando é necessário, sem multiplicar as palavras, e ensina através de gestos de amor e misericórdia. Assim, na pessoa humana e divina de Jesus, manifesta-se a pedagogia redentora em que a humanidade da divindade se torna o parâmetro e meta do ser humano feito à imagem do Criador. ${ }^{13}$

Tendo Jesus como paradigma do educador, podemos refletir sobre o entendimento cristão do ato educativo. De acordo com a Campanha da Fraternidade 2022, educação "[...] não é condicionamento ou adestramento. É conduzir e acompanhar a pessoa para sair do não saber, rumo à consciência de si mesma e do mundo em que vive. É tornar a pessoa consciente, para que se torne sempre mais sujeito de seus sentimentos, pensamentos e ações". ${ }^{14}$ Observando a forma como Jesus lida com a situação de violência e pedagogicamente abre os olhos dos acusadores para a hipocrisia da sentença contra a mulher adúltera, aprendemos que respeito e valorização da dignidade da pessoa constitui-se um axioma fundamental do ato educativo. ${ }^{15} \mathrm{O}$ laboratório da pandemia também nos ensinou na prática que educar é mais que instruir, é saber aprender com as dificuldades e problemas que acontecem na nossa vida real de cada dia e assim nos tornarmos mais humanos e solidários. ${ }^{16}$ "A crise desencadeada pela COVID-19 fez ecoar a perspectiva humanista da educação. É preciso educar para viver em comunhão. Educar para conceber a democracia como um estado de participação". ${ }^{17}$

Carlos Rodrigues Brandão explica que educar é sempre um ato comunitário de tornar algo em comum: "A natureza do homem, na sua dupla estrutura corpórea e espiritual, cria condições especiais para a manutenção e transmissão da sua forma particular e exige organizações físicas e espirituais, ao conjunto das quais damos o nome de educação". ${ }^{18}$ Portanto, "não se pode reduzir a educação apenas à transmissão de conhecimentos", ${ }^{19}$ é

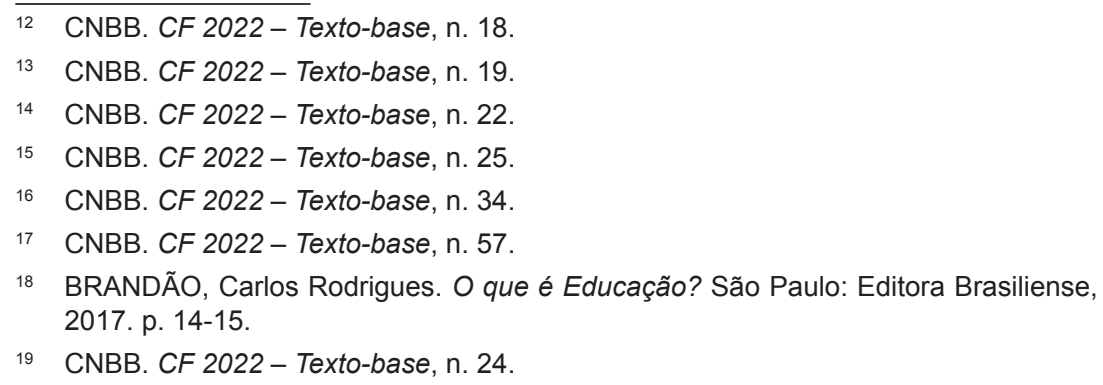


um compartilhar das experiências e saberes que a vida com outros nos proporciona. Nesse sentido, é importante articular o projeto de vida pessoal com o projeto de sociedade que deseja ajudar a construir, colocando no plano particular a meta de trabalhar pelo bem comum e por uma sociedade mais igualitária. Assim, como cristãos, tomamos parte na ação salvífica de Cristo, que é fundamento da educação cristã integral.

A prova do amor de Deus pelo mundo, a entrega consciente e decisiva de Jesus na cruz demonstra nossa interdependência e corresponsabilidade pela nossa casa comum e que cada ato pessoal em prol da vida no planeta nos faz mais membros uns dos outros, coligados no Corpo Místico e Encarnado de Cristo: "a salvação garantida pelo sacrífico redentor de Jesus Cristo é uma salvação integral, que envolve todas as pessoas e cada pessoa no seu todo, isto é, em todas as suas dimensões na concretude histórica". ${ }^{20}$

Para se pensar numa educação integral, é necessário ampliar nossa noção da realidade, abarcando os fatores sociais, culturais, econômicos e biográficos do educador e educandos. ${ }^{21}$ Pois, "uma sociedade que se fecha em um projeto educativo apenas técnico, pragmático e utilitário, empobrece o horizonte existencial das pessoas e anula a sua capacidade criativa". ${ }^{22}$

Na tese concluída em 2021, Emarianne Campanha Teixeira conceitua educação integral como "prática educativa que favorece a formação da pessoa em todas as suas dimensões". ${ }^{23}$ A pesquisadora acredita que a educação integral é uma das alternativas para a humanização do cosmos e da história, uma forma de ensino não apenas voltada a "como fazer", mas buscando as razões nos ensinamentos cristãos do "porquê" fazer. O Papa Francisco esclarece na Laudato $S i$ que a crise ecológica é também crise humanitária e educativa. Só a partir de nova consciência e novos hábitos é possível vencer os graves problemas ambientais que atingem todo o planeta.

Muitos estão cientes de que não basta o progresso atual e a mera acumulação de objetos ou prazeres para dar sentido e alegria ao coração humano, mas não se sentem capazes de renunciar àquilo que o mercado lhes oferece. Nos países que deveriam realizar as maiores mudanças nos

20 CNBB. CF 2022 - Texto-base, n. 30.

21 CNBB. CF 2022 - Texto-base, n. 56.

22 CNBB. CF 2022 - Texto-base, n. 63.

23 TEIXEIRA, Emarianne Campanha. Caminhos da Educação Integral Católica: Do Horizonte do Concílio Vaticano II às Trilhas Educacionais Brasileiras. Tese (Doutorado em Educação) - Universidade Tuiuti do Paraná, Curitiba, 2021, p. 257. 
hábitos de consumo, os jovens têm uma nova sensibilidade ecológica e um espirito generoso, e alguns deles lutam admiravelmente pela defesa do meio ambiente, mas cresceram num contexto de altíssimo consumo e bem-estar que torna difícil a maturação doutros hábitos. Por isso, estamos perante um desafio educativo (LS 209).

Para sair da zona de conforto e mudar velhos costumes de consumo e desperdício, é preciso um espírito firme e decidido a escolher o que é melhor a nós, ao mundo e às futuras gerações. A $L S$ aponta para um caminho educativo ambiental que vai além da mera transmissão de dados e resgata a missão cristã de cuidado com a criação:

A educação ambiental tem vindo a ampliar os seus objetivos. Se, no começo, estava muito centrada na informação científica e na consciencialização e prevenção dos riscos ambientais, agora tende a incluir uma crítica dos «mitos» da modernidade [...] e tende também a recuperar os distintos níveis de equilibrio ecológico: o interior consigo mesmo, o solidário com os outros, o natural com todos os seres vivos, o espiritual com Deus. A educação ambiental deveria predispor-nos para dar este salto para o Mistério, do qual uma ética ecológica recebe o seu sentido mais profundo (LS 210).

A consciência ambiental exige um reordenamento da vida, um crescimento de atitudes solidárias e responsáveis pela natureza e pessoas ao nosso redor, desenvolvendo uma cidadania ecológica e um próprio estilo de vida eco-friendly. Para essa profunda mudança acontecer, não basta apenas transmitir informações e criar leis que não serão seguidas por muitos. É preciso uma transformação da mente e coração, uma conversão ecológica.

Para a norma jurídica produzir efeitos importantes e duradouros, é preciso que a maior parte dos membros da sociedade a tenha acolhido, com base em motivações adequadas, e reaja com uma transformação pessoal. A doação de si mesmo num compromisso ecológico só é possível a partir do cultivo de virtudes sólidas. [...] É muito nobre assumir o dever de cuidar da criação com pequenas ações diárias, é maravilhoso que a educação seja capaz de motivar para elas até dar forma a um estilo de vida. [...] Tudo isto faz parte duma criatividade generosa e dignificante, que põe a descoberto o melhor do ser humano (LS 211).

Maturando sobre este desafio, Francisco propõe o Pacto Educativo Global que visa não apenas uma conscientização sobre o meio ambien- 
te, mas dá um passo adiante para uma educação integral, isto é, educar para a aliança entre o gênero humano e o ecossistema em toda a sua complexidade e pluralidade. Nas últimas décadas o mundo se expandiu e se complexificou com a revolução digital, abrangendo novos espaço de ação e existência humanas. Com a pandemia estes ambientes digitais ganharam tamanha força e vitalidade que não é mais possível pensar numa educação integral sem incluí-los. Por isso, vamos pensar nos desafios e possibilidades educativas que a vida híbrida nos apresenta.

\section{A era on-life: relação entre educação e cultura digital}

"Ser digital vai muito além do aparelhamento tecnológico. Trata-se sobretudo de uma mudança genuinamente paradigmática refletida na cultura e no mindset" ${ }^{24}$ Pensar a educação no contexto digital não é somente implementar sistemas e instalar dispositivos no território escolar, é buscar novas estruturas e caminhos no processo pedagógico cotidiano. Com o ambiente digital, a sala de aula se expande, não se restringindo ao seu espaço físico, pode alcançar qualquer conhecimento em qualquer lugar do mundo.

Este mundo fluído criou outros protagonistas do ensino-aprendizagem que devemos conhecer: "[...] refletir sobre a cultura digital na educação trata-se de levar em consideração esse novo sujeito, um praticante cultural que produz seus saberes, compartilhando conteúdos, informações e opiniões nas redes existentes". ${ }^{25}$ Entender as gerações digitais tornou-se tão fundamental que o novo Diretório para a Catequese fala sobre elas em diversas partes do texto, e dedica uma seção especialmente para abordar a catequese na era digital entre os números 359 e 372. "O digital, portanto, não apenas faz parte das culturas existentes, mas está se estabelecendo como uma nova cultura, modificando primeiramente a linguagem, moldando a mentalidade e reformulando as hierarquias dos valores". ${ }^{26}$

Essas transformações do sujeito, cultura e sociedade trazem consequências diretas para o processo educativo cristão. Dessa forma,

24 CAMARGO, Fausto. A Sala de Aula Digital: Estratégias Pedagógicas para Fomentar o Aprendizado Ativo, On-line e Híbrido. Porto Alegre: Penso, 2021. Edição do Kindle, p. 7. 
a Igreja Católica no Brasil está empenhada na tarefa de educar para a comunicação integral. Antes mesmo do modelo comunicacional em rede se tornar imprescindível para o cultivo comunitário da fé como ocorreu na pandemia, o Diretório de Comunicação da Igreja do Brasil já incentivava as comunidades a promoverem formações para a alfabetização digital de seus membros:

As exigências temáticas de educação para a comunicação precisam estar presentes na formação para o convivio com o mundo digital. A cultura digital requer uma nova lógica formativa, que aproxime os agentes pastorais das maneiras de se expressar, de aprender e de ensinar próprias da sociedade em rede, tendo presente que as tecnologias digitais estão mudando não só o modo de comunicar, mas também a própria comunicação. [...] As novas tecnologias contribuem, nesse contexto, para o surgimento de um "novo sujeito", exigindo que a educomunicação se faça presente para atender aos desafios do atual momento civilizatório. Será oportuno que experiências formativas no campo da alfabetização digital sejam implementadas com as lideranças das várias pastorais envolvidas (DC 234-235).

Mais do que conhecer os nomes e funcionalidades dos mecanismos, é necessário um letramento digital, que "[...] implica tanto a apropriação de uma tecnologia, quanto o exercício efetivo das práticas de escrita que circulam no meio digital". ${ }^{27}$ Portanto, não apenas ler o conteúdo e usar recursos disponíveis no ambiente digital, mas, em meio a este mar de informações, ser capaz de selecionar as que podem contribuir para a sua vida. O passo seguinte é desenvolver a competência crítica midiática, aprender a interpretar informações, identificando sua intencionalidade e tendências, compreendendo suas finalidades e formando sua própria opinião crítica a respeito de seu conteúdo e funcionamento.

Descrevendo o impacto das mídias na educação brasileira, começando com a ampla influência da televisão no povo, o documento aborda as mudanças trazidas pela internet formando gerações digitais com comportamento e processo de aprendizagem próprios: "Introduziram um novo jeito virtual de viver, plasmaram um novo ritmo de tempo, uma nova percepção de distância e um novo modo de viver as relações humanas". ${ }^{28}$ A cultura digital revolucionou a educação ampliando exponencialmente as ofertas de acesso à informações, livros, cursos, vídeos didáticos,

27 RIBEIRO, Ana Elisa. Letramento digital. Belo Horizonte: Autêntica Editora, 2017. Edição do Kindle, p. 57-58.

28 CNBB. CF 2022 - Texto-base, n. 66. 
rede de pesquisadores, etc. A exclusão digital ampliou o abismo social e desigualdade de oportunidades presente na sociedade.

O filósofo italiano e professor da Universidade de Oxford, Luciano Floridi, cunhou o termo on-life para designar a experiência da vida humana contemporânea hiperconectada, "dentro da qual não é mais sensato perguntar se se pode estar on-line ou off-line". ${ }^{29}$ A era on-life é caracterizada pela compreensão das tecnologias da informação e comunicação (TIC's) não como simples ferramentas, mas como forças ambientais que afetam cada vez mais nosso auto-entendimento de quem somos, como nos relacionamos uns com os outros, como entendemos e interagimos com a realidade, modificam, portanto, nossa visão e ação no mundo. ${ }^{30}$ Essas mudanças são consequências do processo de revolução digital, decorrentes de outros acontecimentos anteriores como: Superação do dualismo entre mundo real e virtual; dissipação das barreiras entre ser humano, máquina e natureza; a passagem de uma fase de escassez da informação para uma época de overdose informacional; a mudança do processo autônomo e binário para a dinâmica interativa, interdependente, em rede. ${ }^{31}$

Floridi explica que nós entendemos o mundo a partir de conceitos e nós conceituamos através da observação da realidade. No momento atual, as mudanças em todos os níveis e espectros da realidade são tão drásticas que as terminologias que utilizamos para conceituar o mundo já não nos servem mais. Então, o termo on-life tenta atualizar e suprir a necessidade conceitual de nossa experiência híbrida cotidiana. Esse conceito demonstra reconexão das diversas dimensões da realidade contemporânea, separadas pelo racionalismo moderno.

A era on-life também traz desafios como a cultura dos influenciadores, um fenômeno decorrente da cultura digital, a partir da web 2.0, que proporcionou a possibilidade de pessoas comuns produzirem e divulgarem seu próprio conteúdo através das redes sociais, também causou seu impacto no ensino e no papel do educador atual. Segundo Crystal Abidin, "todo mundo que usa as mídias sociais está se envolvendo em práticas de influência, em certa medida". ${ }^{32}$ Ao analisar o marketing de conteúdo,

29 FLORIDI, Luciano. The Onlife Manifesto. New York, NY: Springer International Publishing, 2015. Edição do Kindle.

30 FLORIDI, Luciano. The Onlife Manifesto.

31 FLORIDI, Luciano. The Onlife Manifesto.

32 ABIDIN, Crystal; KARHAWI, Issaaf. Influenciadores digitais, celebridades da internet e "blogueirinhas": uma entrevista com Crystal Abidin. Intercom - RBCC, São Paulo, 
estratégia muito utilizada por influenciadores, se percebe que ele se baseia em lógicas de ensino-aprendizagem, pois o público é formado a partir de técnicas ensino e compartilhamento de conteúdo que atrai a um grupo de pessoas e acaba por entrar nessa dinâmica de influência. Em muitos casos, o testemunho de um influenciador vale mais para o educando do que a palavra de seu educador. Esse poder de influência real ou aparente está desestabilizando as estruturas baseadas em autoridade.

Para se chegar a uma educação on-life, portanto, exige-se a integração dos espaços físico e digital numa mesma ecologia de ensino que proporcione uma experiência de ensino-aprendizagem mais humanizada e humanizadora: “[...] tanto a educação formal e informal, presencial e virtual, devem promover a liberdade da pessoa humana. Educar é humanizar. A educação é um ato de amor e esperança no ser humano". ${ }^{33}$ Uma das maiores contribuições da cultura on-life é a reunificação de corpo, alma e espírito, fragmentados por certas ideologias e a recuperação da codependência e corresponsabilidade de todos os seres no universo.

Esse espírito de colaboração vem ao encontro do movimento de retomada da sinodalidade que a Igreja Católica está promovendo. A fim de catalisar o processo educativo sinodal trazemos a contribuição da abordagem de Interação Centrada no Tema, da psicoterapeuta judia-alemã Ruth C. Cohn.

\section{Educar para a sinodalidade através da abordagem de Interação Centrada no Tema (ICT)}

De 2021 a 2023, a Igreja está em saída sinodal. Este é um processo eclesial de forte sentido educativo, pois construímos nosso conhecimento sobre a Igreja no mundo de hoje em conjunto com todas as irmãs e irmãos da fé, inclusive com as pessoas não crentes. Ao apresentar a origem da palavra "sínodo", que etimologicamente significa "caminhar com", o documento da Comissão Teológica Internacional recorda que os cristãos foram primeiramente conhecidos como "os discípulos do caminho". ${ }^{34}$ Essa lembrança é importante para entendermos a conjuntura atual da

v. 44, n. 1, p. 289-301, jan./abr. 2021, p. 297.

33 CNBB. CF 2022 - Texto-base, n. 69.

34 COMISSÃO TEOLÓGICA INTERNACIONAL. A sinodalidade na vida e missão da Igreja. Roma, 2018. Disponível em: https://www.vatican.va/roman_curia/congregations/ cfaith/cti_documents/rc_cti_20180302_sinodalita_po.html. Acesso em: 6 nov. 2021. 
Igreja. Ser povo de Deus é ser discípulas e discípulos do caminho, em saída missionária.

O Papa Francisco resgata a identidade sinodal da Igreja e a repropõe como medida para enfrentarmos os desafios contemporâneos: "Caminhar juntos é a via constitutiva da Igreja; a peculiaridade que nos permite interpretar a realidade com os olhos e o coração de Deus; a condição para seguir o Senhor Jesus e ser servos da vida neste tempo ferido". ${ }^{35}$ Através deste sínodo da sinodalidade, ele convoca o povo de Deus a um peregrinar conjunto na parresia do Espírito, composto por três fases: diocesana, continental e universal. É a maior escuta de toda a história da Igreja, é um chamado à cooperação na construção da Igreja como casa da mãe, com suas portas sempre abertas a todas e todos.

Caminhar juntos não significa perder a autonomia, pois para colaborar precisamos ter convicção de nossas ideias e escolhas, ser nossa própria chairperson. ${ }^{36}$ Dessa forma, abordagens pedagógicas humanísticas que valorizam o trabalho em grupo como a Interação Centrada no Tema criada pela psicoterapeuta judia-alemã Ruth C. Cohn podem nos ajudar.

Após sua fuga do nazismo, a psicoterapeuta Ruth Cohn chega à América e desenvolve uma abordagem humanística de trabalho em grupo a fim de que tragédias humanas como o Holocausto jamais se repitam. A Interação Centrada no Tema (ICT) visa despertar nos participantes de um grupo ou equipe "o espírito de cooperação e de corresponsabilidade pelo mundo ao nosso redor, bem como o sentimento de comunidade humana". ${ }^{37} \mathrm{Um}$ dos principais objetivos dessa abordagem é incentivar o "Living Learning", traduzido como "Aprendizagem Viva", que é uma concepção holística de ensino-aprendizagem que trabalha todos os aspectos do ser humano: físico, emocional, intelectual, espiritual e social. ${ }^{38}$

35 FRANCISCO. Discurso do Papa Francisco por ocasião da abertura da $70^{a}$ Assembleia Geral da Conferência Episcopal Italiana. 12 maio 2017. Disponível em: https://www.vatican.va/content/francesco/pt/speeches/2017/may/documents/papa-francesco_20170522_70assemblea-cei.html. Acesso em: 6 nov. 2021. Isto significa que temos autoridade sobre nós mesmos, somos nosso próprio governante. SILVA, Aline Amaro da. Amigas e amigos no Amigo: Uma Cristologia Comunicativa da Amizade em tempos digitais e de pandemia. Tese (Doutorado em Teologia) - Pontifícia Universidade Católica do Rio Grande do Sul, Porto Alegre, 2021.

38 Este tópico é baseado na pesquisa de doutorado da autora, especialmente entre as páginas 65 e 70. 
ICT é um conceito de ação abrangente e holístico que tem o objetivo de moldar situações em que os seres humanos interagem, trabalham, vivem e aprendem juntos, de modo a experimentarem-se conscientemente uns aos outros como humanos e humanizantes. O foco está na ação em grupos, equipes e organizações. O ICT representa um método diferenciado de observação de situações, bem como de controle e acompanhamento de processos sociais. ${ }^{39}$

Essa cultura viva e participativa de aprendizagem se dá através da interação das dimensões "Eu", "Nós", "Isto" e "Globo". ${ }^{40} \mathrm{O}$ "Eu" simboliza cada integrante do grupo, sua biografia, contexto, conhecimento, traços de personalidade. O "Nós" observa como os participantes se entendem e interagem como grupo. "Isto" é o tópico ou atividade a ser realizada, que pode ser individual, em pequenos grupos ou trabalhada em plenária. No "Globo" se considera os contextos e acontecimentos micros e macros ao redor de cada participante, como esses fatores afetam a dinâmica comunitária e influenciam a escolha do tema de engajamento do grupo. Durante o processo de interação, busca-se o balanço dinâmico entre as quatro dimensões, embora certas atividades possam focar predominantemente um dos fatores.

\section{Representação da abordagem ICT}

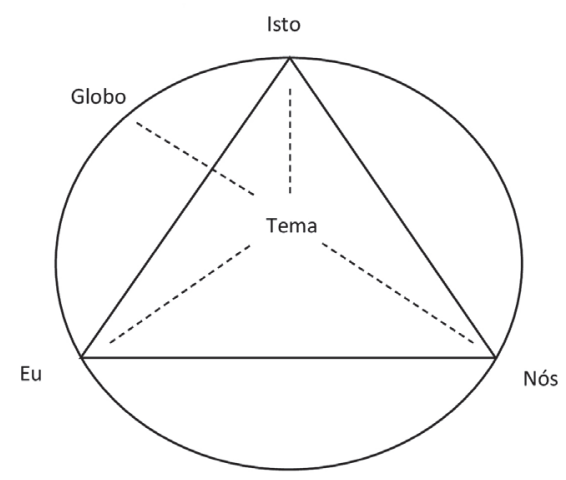

Fonte: SPIELMANN, Jochen. What is TCI? SCHNEIDER-LANDOLF. Handbook of Theme-Centered Interaction, p. 15.

39 SPIELMANN, Jochen. What is TCI? In: SCHNEIDER-LANDOLF. Handbook of Theme-Centered Interaction, p. 14.

40 FORSCHUNGSKREIS KOMMUNIKATIVE THEOLOGIE. Kommunikative Theologie. Selbstvergewisserung unserer Kultur des Theologietreibens. Communicative Theology. Reflections on the Culture of Our Practice of Theology (KomTheolnt, 1/1). Berlin: Lit Verlag, 2007. p. 35. 
Nos vértices do triângulo estão as dimensões "Eu", "Isto" e "Nós", e o círculo que os circunda representa o "Globo". Quem exerce o papel de liderança participativa, além de atuar como integrante do "Nós", analisa a dinâmica interativa entre os quatro fatores para descobrir o "Tema" que o grupo mais se engaja pessoalmente e socialmente, e planejar com a equipe os passos seguintes do processo de atuação. Segundo o especialista em ICT e um dos criadores da Teologia Comunicativa, Matthias Scharer, a concepção do tema de Ruth Cohn é inspirada no conceito de tema gerador de Paulo Freire, o que aproxima a metodologia da tradição pedagógica brasileira e latino-americana de empoderamento dos sujeitos e transformação social. "Com o conceito de "temas geradores", Ruth C. Cohn recorre conscientemente ao pedagogo de libertação Paulo Freire, cujo trabalho já foi associado à ICT em várias ocasiões". ${ }^{41}$ Podemos observar várias aproximações entre as abordagens pedagógicas de Paulo Freire e Ruth Cohn que as diferencia da educação tradicional. Dentre elas, destacamos a função dos interlocutores no processo educativo.

Na visão tradicional, a educação e comunicação são vistas como processos unidirecionais. Isto quer dizer que existe de um lado aquele "detentor do conhecimento" (professor, formador) que transmite a mensagem/conteúdo para "aqueles que não sabem" e que somente recebem a informação (educandos, catequizandos). Já na metodologia de Ruth Cohn e de Paulo Freire, o processo comunicativo é multidirecional. Embora se tenham papéis definidos no desenvolvimento do processo educomunicativo, se reconhece que tanto o líder (moderador, professor, formador) quanto os outros integrantes do grupo (participantes, educandos, catequizandos) possuem conhecimentos e experiências que também compartilham no encontro e que essa troca e interação entre todos é o que gera e produz novos saberes individuais e coletivos. ${ }^{42}$

Além da contribuição freiriana, o ICT tem postulados e axiomas basilares para se constituir uma abordagem humanística e holística. $\mathrm{O}$ postulado "chairperson" incentiva a maturidade e o empoderamento da pessoa, governante de seu próprio destino e sua corresponsabilidade sobre si, sobre os outros e sobre o mundo. Já o segundo postulado, sobre o distúrbio, aponta que as perturbações no grupo podem ser oportunidades

41 SCHARER, Matthias. Vielheit couragiert leben. Die Politische Kraft der Themenzentrierten interaltion (Ruth C. Cohn) heute. Stüttgart, Deutschland: Grünewald Verlag, 2021. p. 211.

42 SILVA, Aline Amaro da. Amigas e amigos no Amigo, p. 106. 
de aprofundamento da relação entre os integrantes, reflexão e descoberta de pontos de engajamento no tema. ${ }^{43}$

São três os princípios que norteiam a abordagem ICT. ${ }^{44} \mathrm{O}$ primeiro é o antropológico que afirma a unidade psicobiológica da pessoa como ser autônomo, ao mesmo tempo que faz parte do ecossistema vivo, interdependente e interconectado. $\mathrm{O}$ axioma ético diz que somos corresponsáveis por toda a vida no planeta, por isso devemos tratar a natureza com respeito e cuidado. Por fim, o enunciado político-pragmático demonstra a crença de Ruth Cohn na capacidade humana de se emancipar e tornar-se livre, transpondo os limites condicionados socialmente. Esses pilares humanos impulsionam o espírito de fraternidade, colaboração e corresponsabilidade pelo universo. A pensadora judia-alemã defende que o êxito no processo psicopedagógico depende da relação estabelecida entre seus interlocutores, caracterizada pela confiança, empatia, respeito e reciprocidade. Ela diz ainda que a maturidade humana cresce no balanço entre autonomia e dependência, proximidade e distância, a consciência de si e do outro, favorecendo um discernimento mais completo da realidade. ${ }^{45}$

A abordagem ICT é utilizada em diversas áreas de atuação como na educação, psicologia, administração e teologia, especialmente para formação de liderança participativa, mas pode ser incorporada em todas as situações cotidianas em que interagimos com pessoas. Dessa forma, a ICT transforma-se em processo criativo de conhecimento sobre si, sobre os outros, sobre o globo, uma alternativa psicopedagógica para uma vida e educação cristã integral.

\section{Conclusão: perspectivas e possibilidades para uma educação cristã on-life}

O Pacto Educativo Global e a Campanha da Fraternidade 2022 nos impulsionam para uma educação cristã integral. O período estendido de pandemia nos moveu ainda mais velozmente para adentrarmos numa experiência de realidade on-life. A Igreja Católica no mundo inteiro dá passos no caminho de retorno à sinodalidade.

43 RUBNER, Angelika. The Psychoanalytic Foundation of TCI. In: SCHNEIDER-LANDOLF. Handbook of Theme-Centered Interaction, p. 320.

44 FORSCHUNGSKREIS KOMMUNIKATIVE THEOLOGIE. Kommunikative Theologie, p. 99-103.

45 REISER, Helmut. The Educational-Pedagogical Fundamentals of TCI. In: SCHNEIDER-LANDOLF. Handbook of Theme-Centered Interaction, p. 42-43. 
Observando e interpretando os sinais dos tempos que nos apresentam, buscamos conectar todos esses acontecimentos importantes na atualidade e relacioná-los com os desafios e possibilidades educativas. Propomos assim, uma educação cristã on-life, que forme todas as dimensões do ser humano para uma vida madura, responsável e plena, que integre numa mesma realidade educativa todos os espaços que o humano transita e habita, seja físico ou digital.

Para isso, é necessário dar preferência a metodologias ativas de ensino-aprendizagem como o Live Learning e o Método Paulo Freire que envolvem teoria e prática em realidades concretas. Neste artigo, destacamos a abordagem de Interação Centrada no Tema, que dá base para o Live Learning, como opção de caminho para a educação cristã on-life, integral e sinodal.

Empenhado em transformar a catequese em "laboratório do diálogo", o Diretório para a Catequese traz caracterizações que se aproximam das dimensões trabalhadas na abordagem ICT: "O Evangelho não se destina à pessoa abstrata, mas a cada pessoa, real, concreta, histórica, inserida em um contexto particular e marcada por dinâmicas psicológicas, sociais, culturais e religiosas". ${ }^{46}$ Estas atribuições também estão em sintonia com as orientações do Diretório Geral de Catequese voltadas para a educação da fé na família, mas que servem hoje para todos os âmbitos de um ensino cristão que busca ser integral e integrador: "[...] trata-se de uma educação cristã mais testemunhada do que ensinada, mais ocasional do que sistemática, mais permanente e cotidiana do que estruturada em períodos" ${ }^{47}$ Caminhamos juntos rumo à uma educação cristã on-life, uma aprendizagem viva da Palavra encarnada e testemunhada em todos os âmbitos da nossa vida hodierna.

\section{Referências}

ABIDIN, Crystal; KARHAWI, Issaaf. Influenciadores digitais, celebridades da internet e "blogueirinhas": uma entrevista com Crystal Abidin. Intercom - RBCC. São Paulo, v. 44, n. 1, p. 289-301, jan./abr. 2021.

46 PONTIFÍCIO CONSELHO PARAA PROMOÇÃO DA NOVA EVANGELIZAÇÃO. Diretório para a Catequese. Brasília: Edições CNBB, 2020. n. 224.

47 CONGREGAÇÃO PARA O CLERO. Diretório Geral para a Catequese, n. 255. Roma, 1998. Disponível em: https://www.vatican.va/roman_curia/congregations/cclergy/documents/rc_con_ccatheduc_doc_17041998_directory-for-catechesis_po.html. Acesso em: 7 nov. 2021. 
BRANDÃO, Carlos Rodrigues. O que é Educação? São Paulo: Editora Brasiliense, 2017.

CAMARGO, Fausto. A Sala de Aula Digital: Estratégias Pedagógicas para Fomentar o Aprendizado Ativo, On-line e Híbrido. Porto Alegre: Penso, 2021. Edição do Kindle.

COMISSÃO TEOLÓGICA INTERNACIONAL. A sinodalidade na vida e missão da Igreja. Roma, 2018. Disponível em: https://www.vatican.va/ roman_curia/congregations/cfaith/cti_documents/rc_cti_20180302_sinodalita_po.html. Acesso em: 6 nov. 2021.

CONFERÊNCIA NACIONAL DOS BISPOS DO BRASIL. CF 2022 - Texto-base. Brasília, DF: Edições CNBB, 2021. Edição do Kindle.

CONFERÊNCIA NACIONAL DOS BISPOS DO BRASIL. Diretório de Comunicação da Igreja no Brasil. Brasília: Edições CNBB, 2014.

CONGREGAÇÃO PARA O CLERO. Diretório Geral para a Catequese. Roma, 1998. Disponível em: https://www.vatican.va/roman_curia/ congregations/cclergy/documents/rc_con_ccatheduc_doc_17041998_ directory-for-catechesis_po.html. Acesso em: 7 nov. 2021.

FLORIDI, Luciano. The Onlife Manifesto. New York, NY: Springer International Publishing, 2015. Edição do Kindle.

FORSCHUNGSKREIS KOMMUNIKATIVE THEOLOGIE / COMMUNICATIVE RESEARCH GROUP. Kommunikative Theologie. Selbstvergewisserung unserer Kultur des Theologietreibens. Communicative Theology. Reflections on the Culture of Our Practice of Theology (KomTheoInt, 1/1). Berlin: Lit Verlag, 2007.

FRANCISCO. Mensagem do Papa Francisco para o Lançamento do Pacto Educativo. Roma, 2019. Disponível em: https://www.vatican.va/ content/francesco/pt/messages/pont-messages/2019/documents/papa-francesco_20190912_messaggio-patto-educativo.pdf. Acesso em: 29 out. 2021.

PONTIFÍCIO CONSELHO PARA A PROMOÇÃO DA NOVA EVANGELIZAÇÃO. Diretório para a Catequese. Brasília: Edições CNBB, 2020.

RIBEIRO, Ana Elisa. Letramento digital. Belo Horizonte: Autêntica Editora, 2017. Edição do Kindle. 
SCHARER, Matthias. Vielheit couragiert leben. Die Politische Kraft der Themenzentrierten interaltion (Ruth C. Cohn) heute. Stüttgart, Deutschland: Grünewald Verlag, 2021.

SCHNEIDER-LANDOLF, Mina; SPIELMANN, Jochen; ZITTERBARTH, Walter. Handbook of Theme-Centered Interaction (TCI). Göttingen: Hubert \& Co., 2017.

SILVA, Aline Amaro da. Amigas e amigos no Amigo: Uma Cristologia Comunicativa da Amizade em tempos digitais e de pandemia. Tese (Doutorado em Teologia) - Pontifícia Universidade Católica do Rio Grande do Sul, Porto Alegre, 2021.

TEIXEIRA, Emarianne Campanha. Caminhos da Educação Integral Católica: Do Horizonte do Concílio Vaticano II às Trilhas Educacionais Brasileiras. Tese (Doutorado em Educação) - Universidade Tuiuti do Paraná, Curitiba, 2021. 